\title{
Bioactive Foods and Nutraceutical Supplementation Criteria in Cardiovascular Protection
}

\author{
Rakesh Sharma* and Ram B. Singh
}

Department of Engineering and Technology, Tallahassee Community College, Tallahassee, Florida 32304, USA

\begin{abstract}
Nutraceuticals are natural and commonly found in bioactive foods or whole plants to keep energy balance in the body and promise substantial therapeutic value in cardioprotection. Major cardioprotective bioactive foods and nutraceuticals are now part of nutrition supplements at nonprescription counters and their self-prescription is increased at large scale. The literature suggests the growing use of new bioactive foods and nutraceuticals in cardioprotection and management. The biochemical mechanisms of nutraceutical action in cardioprotection are poorly reported. The literature indicates the success of fish oils, nutaceuticals in vegetable fat-free diets and restricted life style to enhance cardioprotection. The present paper highlights the need and benefits of newly introduced bioactive foods and revisits the cardioprotective mechanisms of bioactive foods and nutraceuticals. Broadly cardioprotective nutraceuticals are polyunsaturated fatty acids, antioxidants, omega-3 fatty acids, vitamins, minerals and dietary fibers. Most of the nutraceuticals act as biochemical metabolites by direct intervention in intermediary lipid metabolism or regulating proteins of vascular system responsible of 'cardiovascular incapability'.
\end{abstract}

Keywords: Cardioprotection, immunity, nutraceuticals, metabolites, diet, fat, nutraceutical supplementation.

\section{INTRODUCTION}

The term "bioactive foods" was first defined as "foods, food ingredients or dietary supplements that demonstrate specific health or medical benefits including the prevention and treatment of disease beyond basic nutritional functions". Now bioactive foods and nutraceuticals have emerged as potential supplements in cardiovascular and cancer preventive natural sources from food [1].

Why new bioactive foods are important? Bioactive foods are fortified with nutrients to make them more usable within daily recommended allowences (RDA). These nutrients are rich in vitamins, minerals and nutraceuticals or any food or part of a food that provides health or disease prevention benefits with higher nutrition values. Bioactive foods are served as cuisine line of frozen foods on shelf such as Camden(balanced meal program) for hypertension, high cholesterol, or adult-onset diabetes; Tropicana Products, orange juice; Procter \& Gamble's FruitCal ${ }^{\otimes}$-calcium citrate malate etc. Growth in the bioactive food market has also rocked new combinatorial chemistry and profoundly accelerated the pace of discovery of new bioactive foods such as new higholeic soybean with no trans fatty acids that reduces heart diseases.

Both food industries and pharmaceutical industries have roped up to use bioactive food, pharmaceutical and nutrition products - from drinkable yogurt to mainstream designer bone, heart, and digestive health foods to calcium chews, from sports nutrition bar makers to soy burger manufacturers

*Address correspondence to this author at the Department of Engineering and Technology, Tallahassee Community College, Tallahassee, Florida 32304, USA;

E-mails: rksz2007@gmail.com, rks2004@yahoo.com, rks2004@gmail.com
- bioactive foods are poised to undergo very rapid growth in the coming years. Bioactive foods are designed basically meeting four consumer demands: taste, convenience, simple proposition and price. A successful bioactive food product's bioactive role needs its perceptible health benefit. If a health benefit is clearly understandable, or if the health benefit is clearly perceptible - such as weight loss or stress reduction, or can be easily measured - such as a product that reduces cholesterol, then the product is much more likely to succeed. Now interest is growing for use of bioactive foods in cardiovascular prevention. Recently JIVA ${ }^{\mathrm{TM}}$ a bioactive food made of resveratrol combined with garlic has been advocated as potential cardiovascular prevention formula [2]. Similar bioactive foods are in market by Kellogg Co.-cholesterolreducing foods; Ensemble products - psyllium high fiber reducing cholesterol; Johnson \& Johnson -cholesterollowering margarine, Benecol ${ }^{\circledR}$; Balance Bar Company, Nestlé, Vevey, Switzerland - PowerBar. These bioactive foods work on principle that cancer and heart disease are concerns of fatigue/energy and stress. Tropicana Ultimate Smoothie combined with Galaxy's soy, rice and oats Veggie Milk $^{\circledR}$ base with Tropicana's fruit juices. It was estimated that major benefactors were subjects with heart disease $(75 \%)$, cancer $(81 \%)$ including breast cancer $(48 \%)$, colon cancer $(37 \%)$ and prostate cancer $(25 \%)$ using bioactive foods [3]. The bioactive foods as part of daily diet and lifestyle guidelines for prevention of coronary artery disease (CAD) have been evidenced as a major interest during the last few decades.

The concept of bioactive foods was initially considered as natural foods to provide energy as recommended daily requirement in the body to maintain health and lipid lowering till year 1990. Later the importance of nutraceuticals was 
realized as beneficial in different cardiovascular disorders with growing use of the nutraceuticals as self prescription in cardiovascular and developmental conditions in the last decade. In new era of $21^{\text {st }}$ century showed enormous growing awareness of nutraceuticals as emerging potent therapeutic supplements with accepted concept of nutraceutical medicine as new branch of "complementary and alternative medicine'(CAM). In last three decades, national and federal bodies accepted nutraceuticals as possible neutraceutical therapy in main stream of medical education and health. The healthcare industry demonstrated the shift of growing population from medical treatment of dreaded cardiac arrest towards non-prescription nutraceuticals as self-medication in acute coronary syndrome and coronary heart disease management and prevention of stroke. The best examples to mention are Atkin's diet for lipid lowering and CoQ10 for reducing thrombosis. The growing awareness of nutraceutical benefits and shift of healthcare economics in favor of nutraceuticals brought neutraceutical medicine in spotlight of government health policy on systematic use of nutraceuticals in cardiac protection and control of various coronary heart and cardiovascular diseases. In last sixteen years, National Heart Lung Institute (NHLI) and other global efforts have documented the fact sheets and several health documents on nutraceuticals in cardiovascular disease control. The major efforts were devoted in investigation of cardioprotective effect of active nutraceutical component(s) on reduced atherosclerosis plaque development, reduced coronary occlusion, cholesterol desaturation to result the reduced risk of cardiac arrest, heart failure and reduced risk of atherosclerosis and hypertension in initial stages. In last two decades the use of nutraceuticals in prevention and disease control has been extended further as protective nutrition supplementation policy of center of disease control (CDC) under its independent supervision. However, mechanisms still remain unproven and unvalidated but practice of newly discovered nutraceuticals as food supplements in cardioprevention is acceptable.

\section{What are Cardioprotective Nutraceuticals in Bioactive Foods?}

Nutraceuticals are natural bioactive chemical compounds common in bioactive foods as products supplied from nutrition industries. Nutraceuticals have value in health promoting, disease preventing or semi-medicinal properties. $\mathrm{Nu}$ traceuticals are found as natural products from (a) the food industry, (b) the herbal and dietary supplement, (c) pharmaceutical industry, and (d) the newly emerged bioengineered microorganisms, agroproducts or active biomolecules. It may range from isolated nutrients, herbal products, dietary supplements and diets to genetically engineered "custom" foods and processed products such as cereals, soups and beverages. Chemically the nutraceuticals may be classified as isoprenoid derivatives (terpenoids, carotenoids, saponins, tocotrienols, tocopherols, terpenes), phenolic compounds (couramines, tannins, ligrins, anthrocynins, isoflavones, flavonones, flavanoids), carbohydrate derivatives (ascorbic acid, oligosaccharides, non-starch PS), fatty acid and structural lipids (n-3 PUFA, CLA, MUFA, sphingolipids, lecithins), amino acid derivatives (amino acids, allyl-S compounds, capsaicnoids, isothiocyanates, indols, folate, choline), microbes (probiotics, prebiotics) and minerals ( $\mathrm{Ca}, \mathrm{Zn}, \mathrm{Cu}, \mathrm{K}, \mathrm{Se}$ ) [4]. However, the nutraceuticals were reported as active natural compounds. Majority of cardiovascular prevention evidence comes from clinical trials and animal studies [5, 6]. Self-described testimonies of nutraceutical medicine and its success accrued over years in favor of cardiovascular protection by lycopene, glucans(for cardiovascular disease), noni Morinda citrifolia (for relief in blood pressure, muscle pain) [7, 8]. Recently, the antiarrythmic effect of quercetin, lipid lowering effect of fish oils and beneficial effect of magnesium were reported including them as cardioprotective food supplements [9-11].

\section{Dilemma of Nutraceuticals in Cardioprotection}

Nutraceuticals may act as essential nutrient, as drug like, as regulatory biochemical metabolite and as phytohormone in the body as shown in Table 1. Most of the side effects of nutraceuticals remain undocumented and unnoticed. Recently, some prominent evidences are reported in favor of cardiovascular disease inhibitory metabolic activity of nutraceuticals in the human body:

1. Nutraceuticals may act as essential amino acid drug like essential nutrients. For example, tryptophan is needed for protein synthesis at low dose in humans [12].

2. The nutraceutical preparations containing phytosterols are effective in lowering LDL cholesterol [13].

3. Bovine milk fat globule act as anticardiovascular disease, anticholesterolemic, coronary heart disease [14].

4. The phytonutrients prevent myocardial cell proliferation and play significant role in the prevention of chronic degenerative diseases. Notable examples are ginseng, spirulina, gingko biloba, amino acids, glucosamine, chondroitin and Aegle marmelos. Herbal and medicinal plants have shown significant inhibition of cell inflammation [15]. Phytoesterogens play role in reducing myocardial necrosis.

5. Vitamin C, vitamin E, $\beta$-Carotene, lycopene (carotenoids), lipoic Acid, glutathione(thiols) play role in cardiovascular disease prevention and inhibition of necrosis; Co-Enzyme Q-10, super oxide dismastase (enzyme), selenium, copper, manganese, zinc (minerals) act as anticardiovascular disease in cardiac cells [16].

7. Polyunsaturated fatty acids (PUFA) such as safflower oil, corn oil, soybean oil, mustard oil, evening primrose oil, flax oil, hemp seeds, borage seeds showed protective effects in heart disease and stroke, inflammatory arthritis, inflammatory bowel disease, asthma, cardiovascular disease [17].

8. Dietary fibers such as oats, dried beans, legumes, chicory as water soluble fibers, apple, orange, apricot, plum, pine apple contain $18-30 \%$ fiber contents. The fish oils and the vegetable sources such as cabbage, carrot, lettuce, onion, tomato containing 9 to $12 \%$ fiber contents showed antioxidant and myocardial cell proliferation inhibitory properties [18].

9. Wild foods are other major source of nutraceuticals and phytoesterogens. Most of the wild plants, wild mushrooms, wild fungi, wild vegetables, wild nuts, wild fruits and wild flowers as whole are considered as potential natural therapy alternatives rich in long chain omega 3 fatty acids $[19,20]$. 
Table 1. Examples of Nutraceuticals are Shown with Their Benefits in Different Cardiovascular Diseases and Mechanism of Cardioprotective Action in the Body. The Structure of Active Nutraceuticals are Shown with Mechanism and Their Structure with Formula in Chemical Nomenclature

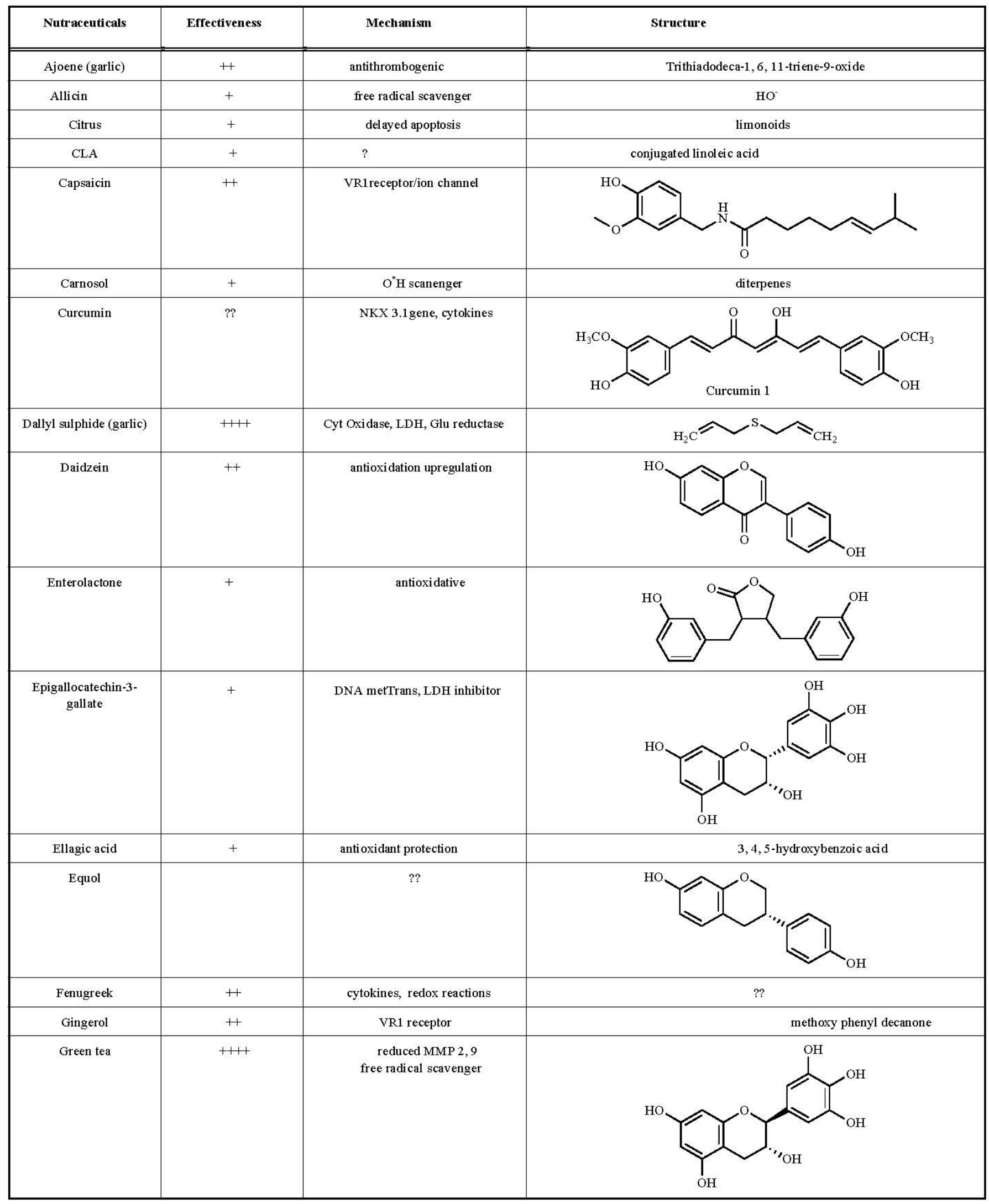


Table 1. Contd...

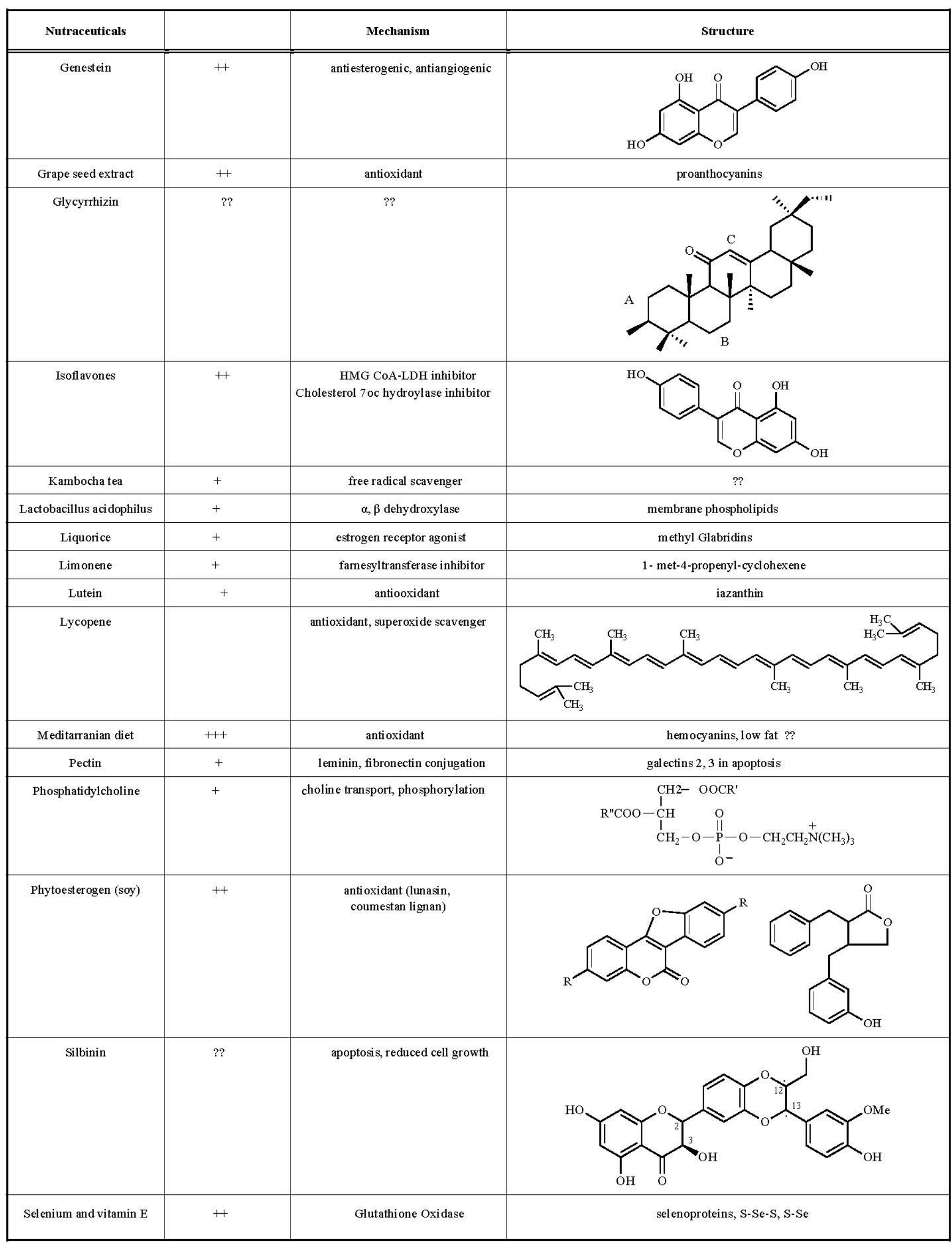


Table 1. Contd....

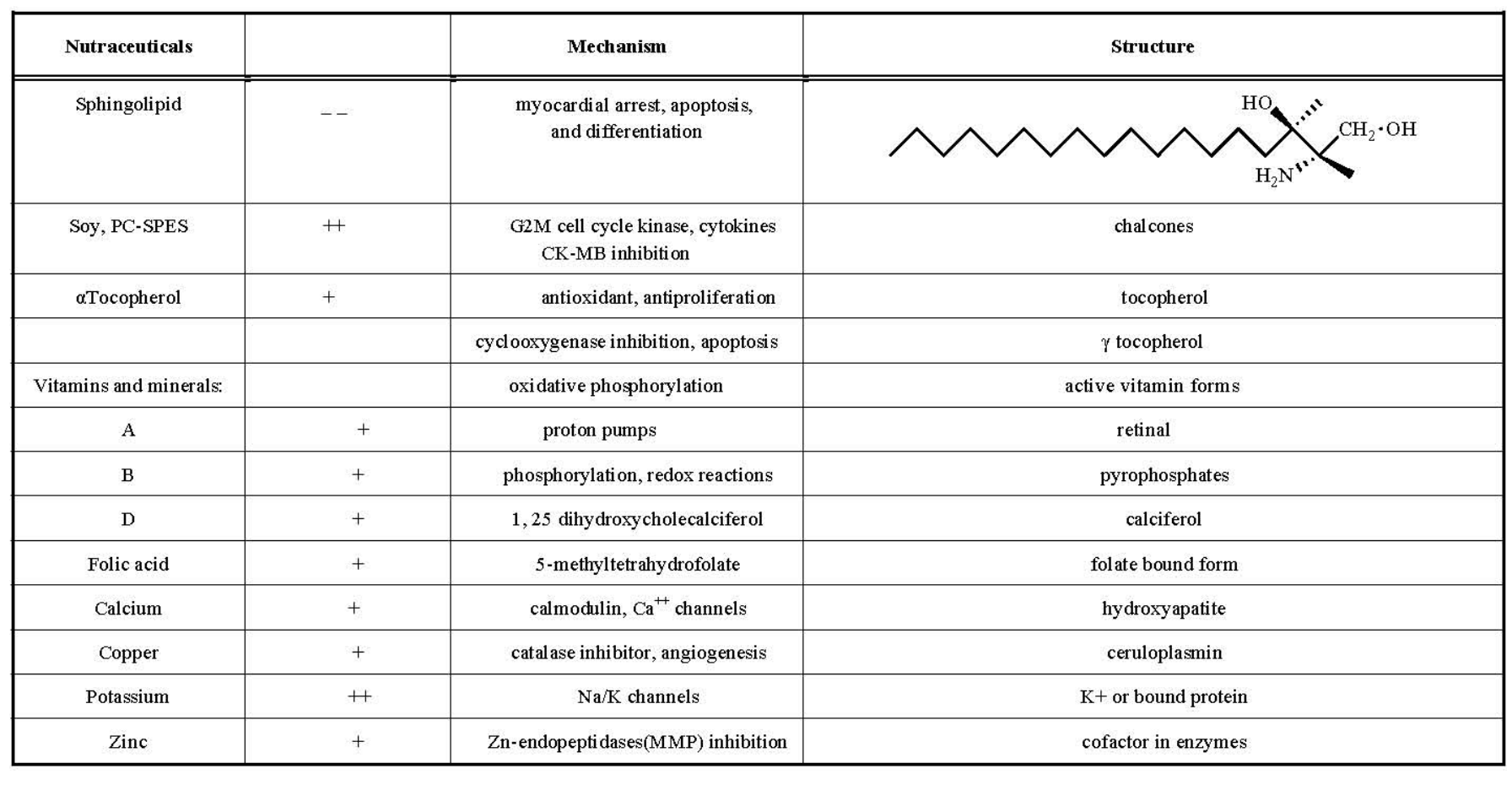

a-linolenic acid $\quad+\quad$ antioxidant $\quad(20: 3, \mathrm{n}-3)$ or ALA

Eicosapentanoic acid ++ $\quad$ antioxidant $\quad(20: 5 ; \mathrm{n}-3)$ or EPA

Docosahexanoic acid ++ antioxidant $\quad$ (20:6; n-3) or DHA

10. Soy isoflavones, genistien, lycopene have emerged as established cardioprotective nutraceuticals. The eicosapentaenoic and docosahexaenoic acids reduce the oxidizability and thrombogenicity [21].

\section{What Remains Still to Solve the Cardioprotection by Nutraceuticals?}

The major issues that remain unsolved are the nutraceutical side effects, dosage and mechanism, follow up consequences and mandatory guide lines of usage. The diet and lifestyle guidelines for prevention of coronary artery disease (CAD) have been evidenced as a major interest during the last few decades. Recommendations of the American heart Association (AHA 2007) have been reformed for better understanding, based on new scientific evidences after publication of guidelines in 2007 [22]. However, none of these guidelines emphasize the role of diet in patients with acute myocardial infarction (AMI) and stroke. Patients presenting with AMI are highly motivated to follow the advice of cardiologist due to serious AMI condition. AMI is associated with hyperglycemia, hyperinsulinemia, hypertriglyceridemia, free radical stress, rise in free fatty acid and pro-inflammatory cytokines, leading to endothelial dysfunction. There happens an acute generation of proinflammatory milieu among AMI patients which is known to cause disruption of atheroma plaque, resulting into re-infarction and death [24-29]. The synergy of these mechanisms in chronic disease is not clear in order to decide the intervention by nutraceuticals such as walnuts, ginko, vegetables [23-29]. Most American experts very deligently advise dietary patterns; including grains, vegetables, fruits, nuts, seeds and legumes, fat and oils based on research studies. Most of the times, the side effects of newly introduced products in market are not documented such as no recommendation for refined starches in the prevention of endothelial dysfunction [24, 30]. However, there is no guideline about the type of oil and type of nuts depending upon the omega-3 fat and monounsaturated fatty acid (MUFA) content of these foods. While foods and beverages with added sugars and refined starches as well as excess of w- 6 , total and saturated fat and trans fatty acids, may be proinflammatory, increased intake of w-3 fatty acid and MUFA may be protective against surge of TNF-alpha,IL6,IL-18 and adhesion molecules like VCAM-1(vascular cell adhsion molecule-1)and IVAM-1 caused by high glycemic, rapidly absorbed proinflammatory foods [27-32]. These foods are known to initiate a proinflammatory milieu in the body which is similar to that of AMI, causing further increase in complications among these patients.

In keeping these facts in mind, it is necessary to identify the concrete evidences of cardioprotective mechanism in both animals and clinical trials under controlled conditions with through investigations, careful nutrition formula design and success rate vs fallacies of earlier clinical experiences in favor of nutraceuticals in public use.

\section{Animal Studies}

A large volume of literature is available on nutraceutical inhibitory effect on cardiovascular disease cell growth based on observations of cultured cardiovascular disease cell proliferation, enhanced apoptosis, antioxidant action etc. Still attempts are in the direction of morphological, cytomorphic, histopathology evidences of nutraceutical induced lipid inhibition and thrombosis by using 3D localized molecular imaging techniques. Previous studies on micro-MRI and immunostaining suggested the reduced apoptosis in experimental rat, mice, rabbit, porcine, dogs experimental models [33]. Major evidence was the reduced oxidative stress, slowed 
down apoptosis, reduced proliferation, less plaque size, less necrosis and poor atherosclerosis growth in treated groups [34]. The mechanism of these nutraceuticals are still not established and it remains to investigate more scientifically diet controlled experimental methods [35-37]. Moreover the beneficial effects of nutraceuticals in experimental animals were reviewed and two third literature reports on nutraceuticals are documented on experimental animal cardiovascular disease studies as either reviews or animal bench experiments on cardiovascular disease prevention. The clinical evidence of nutraceutical cardiovascular disease prevention success is still based on biochemical mechanisms of nutrients in diets reported over several decades. Some mechanisms of nutraceutical action are reported as immune modulatory, induced apoptosis, removal of free radicals, inhibited cell proliferation, inhibited necrosis. New ayurved (Indian traditional medicine) concepts are also emerging as powerful nutraceuticals in cardiovascular disease prevention [38]. The growing literature on mechanism of nutraceutical action in the cardiovascular disease is supporting the extended benefits of nutraceuticals but it further needs more investigations as described in following separate section of new literature evidences [39-41].

\section{Clinical Trials}

Singh and coworkers used 400g/day of fruits, vegetables and legumes in conjunction with mustard oils to decrease the risk of hypertension, diabetes and CAD in 1990s similar with DART, DART II, GISSI [42]. This diet was re-examined by DASH investigators and subsequently by other group to observe the reduced risk of hypertension in USA [43, 44]. In further randomized, controlled intervention trials, Singh et al. 2002, 2008 administered 400 g/day of fruits, vegetables and nuts(almonds and walnuts) and another 400g/day of whole grains including legumes in conjunction with 25$50 \mathrm{~g} /$ day of mustard oils (ALA $2.9 \mathrm{~g} /$ day) in patients with high risk of vascular disease, which showed significant benefit [23, 45-47]. Other workers also found a beneficial effect of fruit, vegetables, nuts and $\omega-3$ fatty acids (EPA+DHA 1.8 g/day) rich foods to patients on risk of coronary artery disease $[46,47]$. A randomized, double blind placebo controlled trial on 300 patients after MI supplemented with EPA+DHA 3.4-3.5 g/day or corn oil showed no change. Increased intake of monounsaturated fatty acid and $\omega-3$ fatty acids have been suggested to be protective against diabetes and metabolic syndrome whereas increased consumption of trans fatty acids, saturated fat and refined starches can predispose CVD. India has a rapid economic development causing increased consumption of salt, tobacco, fat, sugar, and energy in the last four decades. There is increase in per capita income, gross domestic product, food production and automobile production in the last four decades.

This period from 1970 to 2008 has witnessed marked changes in nutraceutical rich diet and lifestyle, particularly in the urban populations among Indians. New bioactive factors have came in light of cardiovascular mechanisms likely affected by nutrients such as: 1. iodine induced T3 and nitric oxide decreases SVR by dilation of the arterioles protein kinase akt pathway via smooth muscle relaxation through nuclear transcription mechanisms [48]; 2. fish consumption
$>300 \mathrm{gm} /$ week reduced non-fatal coronary syndrome (CARDIO2000 study) [49]; 3. transcription of the positively regulated genes (alpha-myosin heavy chain (MHC) and calcium ATPase, SERCA2) both downregulate the expression of negatively regulated genes (beta-MHC and phospholamban) to increase cardiac contractile performance. There is possibility of nutraceutical protection to repair cardiac contractility and improved ejection time (LVET) [49, 50]; 4. improved cardiac output, reduced cardiac preload (low renin state and decreased erythropoietin secretion), increased vascular resistance, bradycardia, slightly depressed myocardial contractility and some increase in LV mass [51]; 5. IF channel, L-type and T-type calcium channel, potassium channel and the ryanodine channel contribute to pacemaker functions and heart rate [52]; 6. dyslipidemia due to total cholesterol and low density lipoproteins (LDL) cholesterol, triglycerides, very low density lipoproteins (VLDL), intermediatedensity lipoproteins, apoprotein A-1 and apoprotein B are observed as well $[53,54] ; 7$. cholesteryl ester transfer protein and hepatic lipase, increased levels of high-density lipoproteins(HDL); 8. endothelial dysfunction, increased arterial stiffness, increased vascular resistance, and hypercoagulability with coronary artery disease [55].

However the effect of bioactive foods is not known if bioactive food affects cardiovascular morbidity or mortality. It might be beneficial to use bioactive food or nutraceuticals as supplements simultaneously with cardioprotective drug therapy. Recently reported noninvasive imaging methods such as Doppler echocardiography, carotid intima-media thickness, pulsed tissue Doppler imaging, cardiac MRI and radionuclide ventriculography to evaulate preejection/ejection ratio systolic dysfunction may be more useful to establish the beneficial effect of nutraceuticals. Overall, trials evaluating cardiovascular mortality and mortality have yielded conflicting results [56].

\section{Biochemical Basis of Nutraceuticals in Cardiac Prevention}

Natural vegetables, herbs, plants, wild foods are complex in structural composition. The biochemical basis of individual source of these foods is not explored due to their complex nature. Some of the evidences are in favor of the active food principles as nutraceuticals to show cardioprotective or preventive supplements. Some of nutraceuticals are in the phase of clinical trial or already available as food supplement. Complementary and Alternative Medicine is emerging in prevention of chronic coronary and heart diseases as safe practice because of the high risk of mortality and long-term morbidity associated with surgical procedures of coronary artery disease and high side effects of chemotherapy. Herbal medicines have shown reduced myocyte cell necrosis in cultured cells. The vitamins, minerals, dietary fat play a role in relation to cardioprevention and control. The mechanisms of nutraceutical action can be discussed broadly in following categories based on active metabolites present in nutraceuticals.

1. Niacin-bound chromium is reported to enhance myocardial protection from ischemia-reperfusion injury [57].

2. Mechanism of the antithrombotic effect was invented by dietary diacylglycerol in atherogenic mice [58]. 
3. Protective effect of potassium against the hypertensive cardiac dysfunction was associated with reactive oxygen species reduction [59].

4. The atherogenic process is reduced by regulation of coenzyme Q10 biosynthesis and breakdown.

5. The n-3 fatty acids reduce the risk of cardiovascular disease. The evidence was explained and mechanisms was explored.

6. Mediterranean diet and optimal diets play role for prevention of coronary heart disease.

7. Alpha-tocopherol therapy was evidenced to reduce oxidative stress and atherosclerosis.

8. Genetic deficiency of inducible nitric oxide synthase reduces atherosclerosis and lowers plasma lipid peroxides in apolipoprotein E-knockout mice.

9. Glutathione is the liver's most abundant protective constituent of antioxidant glutathione reductase enzyme. Glutathione functions as a substrate for the two key detoxification processes in the liver: 1. transforming toxins into water soluble forms, 2. neutralizing and "conjugating" with toxins for elimination through the gut or the kidneys. If either of these processes is impaired for any reason, toxins will accumulate in the body and lead to disease. The best nutrition with liver cardiovascular disease focuses on improving the body's glutathione reserves [60].

10. The Soy isoflavone Haelan951 (genistein and genistin) and garlic allicin were reported to have some role as a cardioprotective in humans [61]. Beta-glycoside conjugate, genistin is abundant in fermented soybeans, soybean products such as soymilk and tofu. Beta-glycosyl bond of genistin is cleaved to produce genistein by microbes during fermentation to yield miso and natto. Soy sauce has high isoflavone but low miso and natto contents. How much soy isoflavones needed? 1.5-4.1 $\mathrm{mg} /$ person miso isoflavone and $6.3-8.3 \mathrm{mg} /$ person natto respectively [62].

11. Green tea has always been considered by the Chinese and Japanese peoples as a potent medicine for the maintenance of health, endowed with the power to prolong life [63].

12. The cardiovascular disease has been reported associated with vascular endothelial growth factor [64].

13. Some herbal plants act as cardioprotective medicine. The herbal extracts are known to reduce the circulating markers of inflammation, including C-reactive protein (CRP), interleukine-6 (IL-6), tumor necrosis factor- $\alpha$ (TNF- $\alpha$ ), serum amyloid A (SAA).

14. Combination of garlic, ginko biloba, herbs with reverastrol inhibited a full 92 percent of age-related gene changes in the heart $[2,64]$.

\section{Lipid Metabolism and Fatty Acid Modifiers as Basis of CVD and role of Nutraceuticals}

Lipid metabolism is established a major factor in cardiovascular protection by supplementing omega fatty acids as described with recent developments for interested readers.
The possible reversal of increased total cholesterol, increased LDL cholesterol, apolipoprotein B and decreased HDL concentrations in cardiovascular patients on bioactive foods and nutraceuticals is controversial [65]. In several trials, total cholesterol levels, HDL, LDL-cholesterol, triglycerides, apolipoprotein A and B and lipoprotein A were not significantly improved with nutraceutical or vitamin-mineral treatment [65]. A trend was noted in favor of nutraceutical therapy with reduced total cholesterol TC level $>240 \mathrm{mg} / \mathrm{dL}$, LDL > $155 \mathrm{mg} / \mathrm{dL}$ TC levels (significant only for >240 $\mathrm{mg} / \mathrm{dL}$ ), and Body Mass Index $>25 \mathrm{~kg} / \mathrm{m}^{2}$ was associated with better improvements [66].

Control of lipid metabolism and cholesterol desaturation in the blood has been cited as major factor in cardiovascular disease. The nutraceuticals have been reported as inhibitors of cholesterol synthesis and enhancing HDL lipoproteins in the body. To explain the effect of nutraceuticals, two major mechanisms play significant role in cholesterol saturation and lipoprotein synthesis. First, HMG CoA synthase enzyme controls the mevalonate to HMG CoA formation that subsequently used in cholesterol formation while cholesterol oxidase enzyme oxidizes cholesterol to desaturate it. Second, cholesterol esterification by LCAT and ACAT enzymes and subsequently apoprotein binding controls the lipoprotein formation [67]. Mainly high density lipoprotein (HDL) plays significant role in scavenging cholesterol from blood as shown in Fig. (1). Low density lipoproteins (LDL) transport is controlled by LDL receptors in the cells. LDL lipoproteins get metabolized by lipo-oxygenase pathway as shown by Fig. (2).

The anti-inflammatory effects and antithrombogenic effects of $\omega-3$ fatty acids are eicosanoid-dependent process. More intake of EPA and DHA fatty acids increases these fatty acids in tissue, cellular and circulating lipids, along with a simultaneous reduction in $\omega-6$ fatty acids. EPA acts as a substrate for both cyclooxygenase (COX) and 5lipoxygenase (5-LOX) enzymes to make derivatives from arachidonic acid (AA) such as leucotriene $\mathrm{B}_{5}\left(\mathrm{LTB}_{5}\right)$ is only about $10 \%$ as potent as $\mathrm{LTB}_{4}$ as a chemotactic agent and in promoting lysosomal enzyme release). The $\omega-3$ fatty acids also result with reduced formation of thomboxane-2 $\left(\mathrm{TxA}_{2}\right)$ and prostacyclin $\mathrm{I}_{2}\left(\mathrm{PGI}_{2}\right)$, as $\mathrm{AA}$ is a $\mathrm{TxA}_{2}$ and $\mathrm{PGI}_{2}$ precursor and inhibiting platelet aggregation (a less thrombogenic state) as shown in Fig. 2).

The fatty acids display major beneficial effects: 1.lipid lowering in blood; 2.antiarrhythmic effect in CHD; 3. antithrombotic effects; 4. anti-atherosclerotic and antiinflammatory effects; 5 . improved endothelial function; and 6. lowering blood pressure.

From biochemistry standpoint, the beneficial effect of $\omega$ 3 fatty acids on blood lipids is by the stimulation of the gene expression of lipoprotein lipase (LPL) enzyme in human adipose tissue with increase in the LPL mRNA. It results with post-heparin LPL activity, in conjunction with the lowering effect of these fatty acids on the triglyceride levels, postprandial lipaemia and the levels of the highly atherogenic, small and dense LDL particles [24]. These fatty acids increase the expression of genes encoding enzymes critical to hepatic and skeletal muscle fatty acid $\beta$-oxidation while repressing genes encoding glycolytic, lipogenic and choles- 


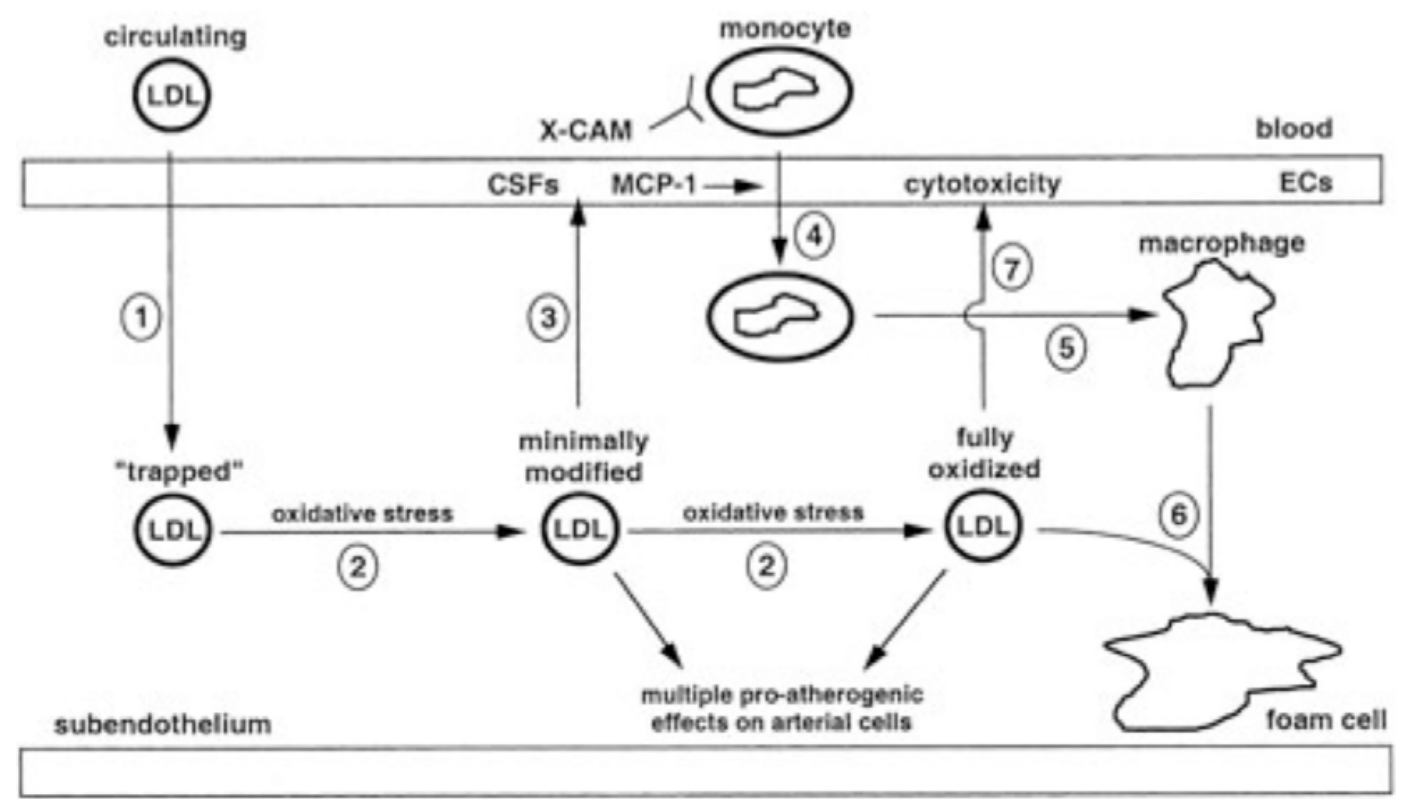

Fig. (1). Proposed role of LDL oxidation in the thrombogenesis and endothelial dysfunction. LDL crosses the endothelium in a concentration-dependent manner and can become trapped in the extracellular matrix (1). The subendothelium is an oxidizing environment, and if the LDL remains trapped for a sufficiently long period of time, it undergoes oxidative changes (2). Mildly oxidized forms of LDL contain biologically active phospholipid oxidation products that affect the pattern of gene expression in endothelial cells (ECs), leading to, among other things, changes in the expression of monocyte binding molecules (designated X-CAM), monocyte chemoattractant protein (MCP-1), and macrophage colony stimulating factors (CSFs) (3). These factors in turn promote the recruitment of monocytes (4) and drive their phenotypic differentiation to macrophages (5). Further oxidation leads to alterations in apolipoprotein B such that LDL particles are recognized and internalized by macrophages (6), progenitors of the lipid-laden foam cells. Marked increases in lipid and cholesterol oxidation products render the LDL particles cytotoxic, leading to further endothelial injury (7) and favoring further entry of LDL and circulating monocytes and thus a continuation of the disease process.

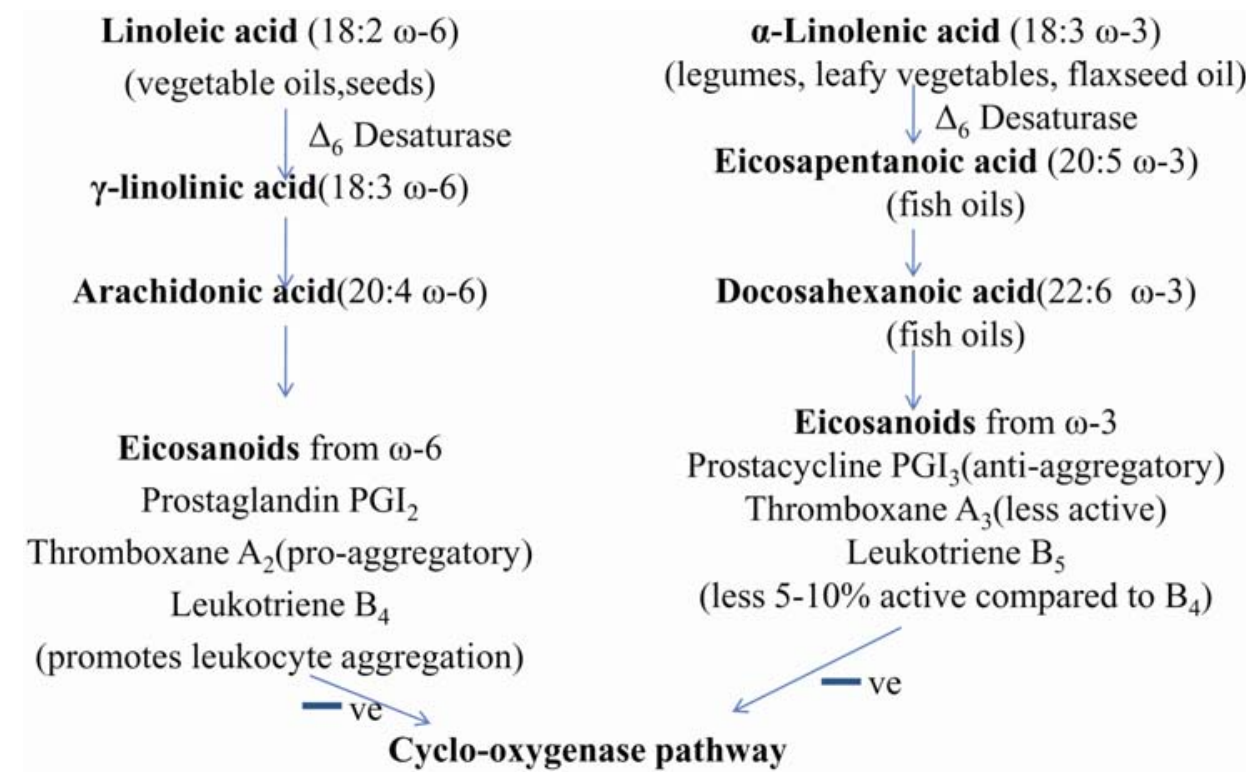

Fig. (2). The omega 3 and omega 6 fatty acids synthesize ecosanoids in the myocardial cells.

terolgenic enzymes. This twofold action results in the decrease in lipid synthesis and a subsequent increase in lipid oxidation favorable for nutraceutical intervention. Despite the fact that the exact mode of action of $\omega-3$ fatty acids is not fully understood, it is speculated that $\omega-3$ fatty acids interact with three nuclear receptors-hepatic nuclear factor (HNF)$4 \alpha$, liver X receptors (LXR) $\alpha$ and $\beta$ and peroxisome prolif- erators- activated receptors (PPARs) $\alpha, \beta$ and $\gamma-$ and by regulating the transcription factor sterol regulatory element binding proteins (SREBPs) 1 and 2[25]. $\Omega-3$ fatty acids also decrease excitability and cytosolic calcium fluctuations of ventricular myocytes via inhibition of $\mathrm{Na}^{+}$and L-type $\mathrm{Ca}^{+2}$ channels. The mechanisms of action of $\omega-3$ fatty acids have not been fully elucidated. 


\section{TREATMENT RECOMMENDATIONS FOR NEUTRACEUTICALS IN CARDIOVASCULAR PREVENTION}

\section{Who Need the Alternative Approaches of Nutraceuticals in CVD}

Children below 18 years probably do not need nutraceuticals. Adults over 20-40 years need nutraceuticals and monitoring CVD. Persons over sixty years in age, need CVD/ CHD watch and nutraceuticals as mandatory daily dietary supplements in practice. These senior persons may show the following major symptoms as causes of cardiovascular disorders and CVD development [68].

- Poor cytokines, inflammatory proteins gradually lead to apoptosis, loss of immunity

- Arteries and veins (and other tissues) become less elastic, as evidenced by our skin. Blood pressure may rise, as arteries lose their elasticity. (The amino acid taurine, found in fish, softens arteries and veins, as well as other connective tissue.)

- Inflammation and cholesterol-filled growths (plaques) in our blood vessels reduce their rates of flow. The loss of elasticity causes the heart to pump with less power and force.

- Insulin levels begin to rise as old cells become less responsive to insulin, and the pancreas increases its output to compensate. This eventually leads to Type II diabetes and pancreatic cardiovascular disease in which old cells no longer respond to insulin and end up with heavy cardiovascular damage and cardiovascular disease.

- Kidneys lose reserve capacity, gradually fail to do normal function and develop cardiovascular disease.

- Reduced cell mediated immunity and humoral immunity leads to immune deficiency and cardiovascular disorders.

\section{Present State of Art on Nutraceutical Medicine in Cardiovascular Prevention}

FDA requires appropriate scientific evidence regarding safety of nutraceutical use as daily prescription. However, new recommendations suggested that daily diet must contain 6.25 grams of soy protein per serving, micro-compound allicin (a small component of garlic) ad libitum amount, ecosapentanoic acid/docosahexanoic acid as polyunsaturated fatty acids (PUFAs) from fish or fish oils. The complementary medicine and alternative medicine approach is emerging as regulated tool to prescribe the norms of nutraceuticals as daily supplements in cardiovascular disease and other diseases [69].

\section{Insurance and Prescription}

National and federal agencies such as NCI and FDA need evidences and established data in large trials to approve nutraceuticals in clinical practice. In lack of such evidences and database, still nutraceutical practice remains at the door steps as nonprescription self-prescription available on counter. As a result, insurance companies still shy to accept nutraceuticals as prescription.
Government Policy: Criteria of Suggested Practice of Nutraceuticals in Cardiovascular Prevention

The awareness of complementary and alternative medicine (CAM) is increasing rapidly among common public in developed countries [69]. Government agencies are actively participating in safe delivery of bioactive foods and dogwatch if any side effect. Several government reports have showed positive role to introduce new functional foods \& nutraceuticals in CVD/CHD prevention in favor of guava, dietary fibers, soy, phystoesterogens, herbs, cruciferous vegetables [70]. Both bioactive food and nutraceuticals in diets were suggested as preventive in cardiovascular disease. Main causative factors of cardiovascular disease were free radicals, vitamin C,D,E deficiency, selenium deficiency and loss of cellular immunity in patients on daily diet [71].

Recently, National Heart and Lung Institute put forth the efforts on alternative ways of cardiovascular disease prevention as public awareness to main focus on life style, prevention and control care measures, eating habits, hazardous contaminants with several successful attempts of antioxidants, garlic, vitamins [72]. Under supervision and dogwatch, most of the bioactive foods on counters and nutraceuticals are marketed as some of them listed in Table $\mathbf{2}$.

\section{Bioactive Foods and Nutraceuticals in CVD/CHD: A Survey}

In recent years during 2002-2008, the major focus was on more evidence based wider use of omega 3 fatty acids combined with multivitamin-multimineral and isolated bioactive components from plants and functional foods in various cardiovascular disease types. In last 4 years maximum efforts were devoted on reviews and compilation of evidenced experimental results on vegetarianism in reducing cardiovascular disease progress and identification of associations of active food components in diet with reduced lipids, myocardial necrosis and apoptosis. However, NHLI views that sequential events during the nutraceutical treated cell growth or arrest cardiovascular disease are controversial [73]. The use of fish oils in elderly patients was revisited if any relation with arrhythmia and contractility. The literature during years 2002-2008 suggested major information for following: 1 . direct link of vitamins, minerals in cardiovascular disease prevention; 2 . new bioactive food components with new mechanism of lipid lowering; 3 . more controlled trials and regulated studies under federal support; 4. new awareness of unpopular foods and common shelf food supplements in cardiovascular disease prevention; 5. new federal and statuary guidelines on nutraceutical recommended allowances and marketing.

The following information is grouped based on literature on nutraceuticals and nutraceuticals in cardiovascular disease management with major focus on controlled randomized trials in experimental cardiovascular diseases and clinical cardiovascular disease subjects. The description is divided into three sections.

I. Bioactive foods and nutraceuticals in cardiovascular prevention during years 2000-2008: Nutraceuticals and local foods were suggested as readily available and their use with possibility of alternative pharmacotherapy to prevent cardio- 
Table 2. The Table Represents the FDA Approved Nutraceuticals with Recommended Quantity and Sources of Nutraceuticals on Shelf in Super Markets

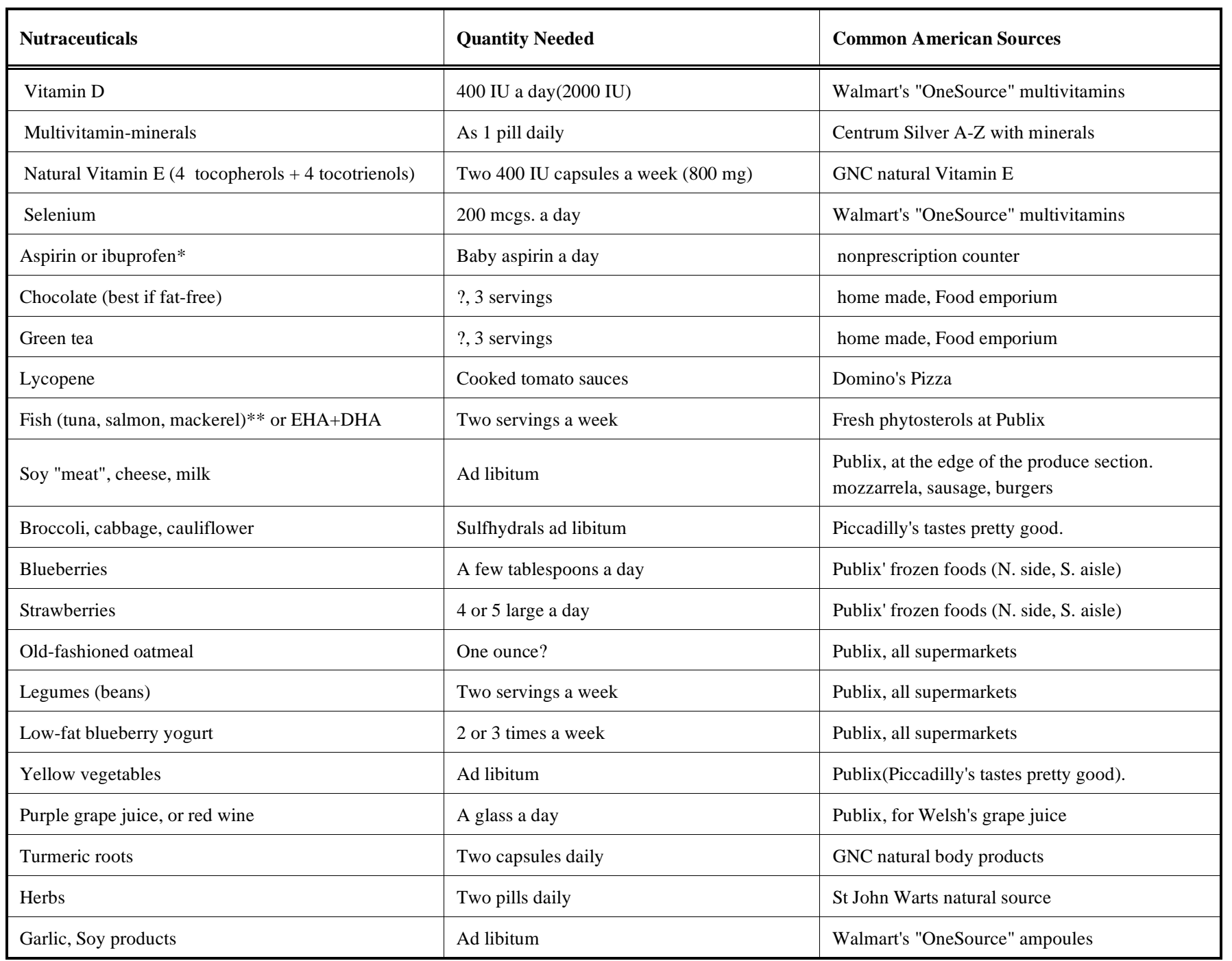

*aspirin and ibuprofen primarily act as anti inflammation. (Other agents such as fish also have anti-inflammatory properties.);**Tuna and mackerel contain mercury, dioxin, and PCB's, The salmon fish is safe. Winn Dixie farm-raised salmon. canned salmon provides omega-3 fatty acids and , taurine which are vital to the nervous and cardiovascular systems (modified from the Source[Sharma 2009]).

vascular diseases [73-75]. Less known bioactive foods containing ephedra and caffeine were reported to improve electrocardiograhic and hemodynamic effects [75]. Clear cardioprotective role of vitamin $\mathrm{E}$ and antioxidant supplements was reviewed in prevention of cardiovascular diseases [76-81]. Homocysteine, taurine, vitamins and omega 3-fatty acids were reinvestigated and confirmed their value in cardiovascular prevention [82-86].

Mechanism of cardiovascular prevention by nutraceuticals: Mainly cholesterol rich dietary fats enhances the risk of coronary heart disease while omega 3/omega 6 fatty acids reduce the risk of cardiovascular diseases and play cardioprotective role in primary, secondary and late- onset diseases [87-89]. Interestingly, the excessive linoleic acid is manifested as 'linoleic acid syndrome' in coronary heart disease [89]. Conjugated lineleic acid was reported as protective against cardiac hypertrophy [90]. Omega 3 fatty acids mainly lower the blood lipids.
II. The possible reasons of cardioprotection by $\omega-3$ fatty acids in bioactive foods were:

- Lipid lowering (reduction of fasting triglycerides, attenuation of postprandial triglyceride response)

- Antiarrhythmic effects

- Antithrombotic and other effects on the haemostatic systems (i.e. reduced platelet reactivity, moderately longer bleeding times, reduced plasma viscosity)

- Inhibition of atherosclerosis and inflammation via inhibition of smooth muscle cell proliferation, altered eicosanoid synthesis, reduced expression of cell adhesion molecules and suppression of inflammatory cytokines production (IL's, TNF- $\alpha$ ) and mitogens

- Improvement of the endothelial function [through enhancement of nitric oxide - dependent and nitric oxide independent vasodilatation] 
- Improvement in blood pressure.

III. CVD/CHD in the human body and nutraceutical protection: Supplementation of fish oils dominate the scenario of lipid lowering in cardiovascular diseases [90]. New candidates such as cinnamon, ginko biloba, bioactive peptides have been introduced in the list of nutraceuticals with cardioprotective properties $[85,91,92]$. In recent detailed report, authors validated that Guggul (Commiphora mukul) herb rich in guggusterones lowers both cholesterol $(30 \%$ in 3 months)and triglycerides. It maintains LDL level (35\% lowering in 3 months) and improves HDL level (20\% in 12 weeks) to keep higher HDL/LDL ratio. It keeps smooth blood flow and maintains thin blood with continuous detoxification and reduced platelet aggregation. It relaxes the muscles and keeps muscle strain low. Additionally, it has properties of rejuvenation and blood purification. Other unique properties are immunomodulation and lipid lowering. Guggul increases body's metabolic rate, improved thyroid function and heat production due to the presence of guggulsterones [93, 94]. Broadly, today it is believed that bioactive foods get digested by natural enzymes and their digested metabolite products target many cardiovascular related intracellular metabolic abnormalities of both focal (targeted cure) and whole body in origin (whole individual or global cure) while its counterpart artificial synthesized pharmaceutical drug either inhibits or elevates only one biochemical reaction with assumption of complete cure. In this single step cure approach, several naturally active enzymes, cofactors and assembly proteins loose their conformation and functioanlity (bioactive behavior) leading to several side effects. These are lesser by bioactive foods or nutraceuticals becuase of their wider acceptance in the body but side effects are very frequent caused by pharmaceutical drugs and still it remains a challenge how to minimize these side effects. Several negative studies exist to advocate the further careful investigations $[93,94]$.

\section{Challenges, Hypes, Hopes and Futuristic role of Nutraceuticals in Cardioprotection}

Most of the success of nutraceuticals is based on selfprescription and own individual experiences. Still it is far to realize the miraculous benefits of nutraceuticals unless controlled clinical trials support the evidences and facts of nutraceutical preventive therapeutic efficacy. Major challenge is early detection of cardiovascular disease and timely effective treatment. In spite of all tools available, cardiovascular disease is major health hazard. The major available data on nutraceutical benefits in cardiovascular disease comes from epidemiological health and population statistics. The reduced cardiovascular disease incidence due to nutraceuticals seems hype but greater hopes are anticipated with advancements in food science. However, still cardiovascular disease remains a major threat because of high mortality compounded with incomplete success of chemotherapy and surgery intervention. In future, bioengineered nutraceuticals will play significant role in CVD prevention as alternative therapeutics.

\section{CONCLUSION}

Bioactive foods with rich nutraceuticals still are growing in number as healthy food products introduced by companies and investigations suggest high hopes of nutraceuticals in cardiovascular disease prevention. The primary focus still remains on dyslipidemia and lipid lowering by fish oils and bioactive foods. The role of governments and globalization will certainly support the health risks and clinical trials on new bioactive foods and nutraceuticals. The nutraceuticals are becoming popular as they are harmless and natural food constituents. The nutraceuticals are still food supplements and last 5 years demonstrated enormous change in the perception of nutraceuticals as cardiovascular disease preventive and therapeutic supplements in cardiovascular diseases of different organs.

\section{ACKNOWLEGEMENTS}

The author acknowledges the opportunity of engineering and biotechnology internship under supervision of Dr. Ching J. Chen at FAMU-FSU College of Engineering, Tallahassee, Florida.

\section{REFERENCES}

[1] German JB, Dillard CJ. Phytochemicals: nutraceuticals and human health. J Sci Food Agric 2000; 80: 1744-56.

[2] Condori J, Medrano G, Sivakumar G, Nair V, Cramer C, MedinaBolivar F. Functional characterization of a stilbene synthase gene using a transient expression system in planta. Plant Cell Rep 2009; 28(4): 589-99.

[3] Sloan Trends \& Solutions, Health Focus 1999.

[4] Dureja D, Kaushik D, Kumar V. Developments in nutraceuticals. Indian J Pharmacol 2003; 35: 363-72.

[5] Malik A, Kumar P, Kaushik N, Singh A. The potential of nutraceuticals. Pharm Rev 2008; 6(2):-

[6] Rishi RK. Nutraceuticals: borderline between food and drug? Pharm Rev 2006; 2: 51-53.

[7] Pawlus AD, Kinghorn DA. Review of the ethnobotany, chemistry, biological activity and safety of the botanical dietary supplement Morinda citrifolia (noni). J Pharm Pharmacol 2007; 59(12): 1587609.

[8] Visioli F, Bogani P, Grande S, Galli C. Mediterranean food and health: building human evidence. J Physiol Pharmacol 2005; 56 (1): 37-49.

[9] Dujardin KS, Dumotier B, David M, Guizy M, Valenzuela C, Hondeghem LM. Ultrafast sodium channel block by dietary fish oil prevents dofetilide-induced ventricular arrhythmias in rabbit hearts. Am J Physiol Heart Circ Physiol 2008; 295(4): H1414-21.

[10] Boots AW, Haenen GR, Bast A. Health effects of quercetin: from antioxidant to nutraceutical. Eur J Pharmacol 2008; 585(2-3): 32537.

[11] Bo S, Pisu E. Role of dietary magnesium in cardiovascular disease prevention, insulin sensitivity and diabetes. Curr Opin Lipidol 2008; 19(1): 50-6.

[12] Navas-Acien A, Bleys J, Guallar E. Selenium intake and cardiovascular risk: what is new? Curr Opin Lipidol 2008; 19(1): 43-9.

[13] Juan YS, Hydery T, Mannikarottu A, et al. Coenzyme Q10 protect against ischemia/reperfusion induced biochemical and functional changes in rabbit urinary bladder. Mol Cell Biochem 2008; 311(12): 73-80.

[14] Spitberg VL. Bovine milk fat globule membrane as a potent nutraceutical. J Dairy Sci 2005; 88: 2289-94.

[15] Hamblin M, Smith HM, Hill MF. Dietary supplementation with vitamin $\mathrm{E}$ ameliorates cardiac failure in type I diabetic cardiomyopathy by suppressing myocardial generation of 8-isoprostaglandin F2alpha and oxidized glutathione. J Card Fail 2007; 13(10): 884-92.

[16] Novgorodtseva TP, Vitkina TI, Karaman IuK, Aminina VF. Application of food supplement on the base of potassium and magnesium at experimental cardiopathology. Vopr Pitan 2007; 76(5): 55-9.

[17] Cybulska I. N-3 polyunsaturated fatty acid in cardiovascular disease. Przegl Lek 2006; 63(8): 685-7.

[18] Ismail HM. The role of omega-3 fatty acids in cardiac protection: an overview. Front Biosci 2005; 10: 1079-88.

[19] Rupp H, Wagner D, Rupp T, Schulte LM, Maisch B. Risk stratification by the "EPA+DHA level" and the "EPA/AA ratio" focus on 
anti-inflammatory and antiarrhythmogenic effects of long-chain omega-3 fatty acids. Herz 2004; 29(7): 673-85.

[20] Mesa MD, Buckley R, Minihane AM, Yaqoob P. Effects of oils rich in eicosapentaenoic and docosahexaenoic acids on the oxidizability and thrombogenicity of low-density lipoprotein. Atherosclerosis 2004; 175(2): 333-43.

[21] Tikkanen MJ, Wähälä K, Ojala S, Vihma V, Adlercreutz H. Effect of soybean phytoestrogen intake on low density lipoprotein oxidation resistance. Proc Natl Acad Sci U S A 1998; 95(6): 3106-10.

[22] Warnes CA, Williams RG, Bashore TM, et al. ACC/AHA 2008 Guidelines for the management of adults with congenital heart disease. J Am Coll Cardiol 2008; 52: 143-263.

[23] Almario RU, Vonghavaravat V, Wong R, Kasim-Karakas SE. Effect of walnut consumption on plasma fatty acids and lipoproteins in combined hyperlipidemia. Am J Clin Nutr 2001; 74: 72-9.

[24] Khan S, Minihane AM, Talmud PJ, et al. Dietary long-chain n-3 PUFA's increase LPL gene expression in adipose tissue of subjects with an atherogenic lipoprotein phenotype. J Lipid Res 2002; 43: 979-85.

[25] Jump DB. Dietary polyunsaturated fatty acids and regulation of gene transcription. Curr Opin Lipidol 2002; 13: 155-64.

[26] Din JN, Newby DE, Flapan AD. Omega 3 fatty acids and cardiovascular disease - fishing for a natural treatment. BMJ 2004; 328: 30-35.

[27] Kris-Etheron PM, Harris WS, Appel LJ. Fish consumption, fish oil, omega-3 fatty acids and cardiovascular disease. Arterioscler Thromb Vasc Biol 2003; 23: e20-e31.

[28] Lopez-Garcia E, Schulze MB, Manson JE, et al. Consumption of (n-3) fatty acids is related to plasma biomarkers of inflammation and endothelial activation in women. J Nutr 2004; 134: 1806-11.

[29] Hjerkinn EM, Seljeflot I, Ellingsen I, et al. Influence of long-term intervention with dietary counseling, long-chain $\mathrm{n}-3$ fatty acid supplements, or both on circulating markers of endothelial activation in men with long-standing hyperlipidemia. Am J Clin Nutr 2005; 81: 583-9.

[30] De Caterina R, Liao JK, Libby P. Fatty acid modulation of endothelial activation. Am J Clin Nutr 2000; 71: 213S-23S.

[31] Hu FB, Willett WC. Optimal diets for prevention of coronary heart disease. JAMA 2002; 288(20): 2569-78.

[32] Harris WS, Reid KJ, Sands SA, Spertus JA. Blood omega-3 and trans fatty acids in middle aged acute coronary syndrome patients. Am J Cardiol 2007; 99: 154-8.

[33] Coombes JS, Powers SK, Hamilton KL, et al. Improved cardiac performance after ischemia in aged rats supplemented with vitamin E and alpha-lipoic acid. Am J Physiol Regul Integr Comp Physiol 2000; 279(6): R2149-55.

[34] Zhou J, Møller J, Ritskes-Hoitinga M, Larsen ML, Austin RC, Falk E. Effects of vitamin supplementation and hyperhomocysteinemia on atherosclerosis in apoE-deficient mice. Atherosclerosis 2003; 168(2): 255-62.

[35] Oudit GY, Trivieri MG, Khaper N, et al. Taurine supplementation reduces oxidative stress and improves cardiovascular function in an iron-overload murine model. Circulation 2004; 109(15): 187785.

[36] Racasan S, Braam B, Van der Giezen DM, et al. Perinatal Larginine and antioxidant supplements reduce adult blood pressure in spontaneously hypertensive rats. Hypertension 2004; 44(1): 838.

[37] Wang Q, Simonyi A, Li W, et al. Dietary grape supplement ameliorates cerebral ischemia-induced neuronal death in gerbils. Mol Nutr Food Res 2005; 49(5): 443-51.

[38] Zampolli A, Bysted A, Leth T, Mortensen A, De Caterina R, Falk E. Contrasting effect of fish oil supplementation on the development of atherosclerosis in murine models. Atherosclerosis 2006; 184(1): 78-85

[39] Esterhuyse AJ, Toit ED, Rooyen JV. Dietary red palm oil supplementation protects against the consequences of global ischemia in the isolated perfused rat heart. Asia Pac J Clin Nutr 2005; 14(4): 340-7.

[40] Zahid AM, Hussain ME, Fahim M. Antiatherosclerotic effects of dietary supplementations of garlic and turmeric: restoration of endothelial function in rats. Life Sci 2005; 77(8): 837-57.

[41] El-Badry AM, Moritz W, Contaldo C, Tian Y, Graf R, Clavien PA. Prevention of reperfusion injury and microcirculatory failure in macrosteatotic mouse liver by omega- 3 fatty acids. Hepatology 2007; 45(4): 855-63.
[42] Samuel SM, Thirunavukkarasu M, Penumathsa SV, Paul D, Maulik N. Akt/FOXO3a/SIRT1-mediated cardioprotection by n-tyrosol against ischemic stress in rat in vivo model of myocardial infarction: switching gears toward survival and longevity. J Agric Food Chem 2008; 56(20): 9692-8

[43] Singh RB, Rastogi SS, Niaz MA, Ghosh S, Singh R, Gupta S. Effect of fat modified and fruits and vegetable enriched diets on blood lipids in the Indian diet heart study. Am J Cardiol 1992; 69: 869-74.

[44] Nilsen DW, Albrektsen G, Landmark K, Moen S, Aarsland T, Woie L. Effects of a high dose concentrate of n-3 fatty acids or corn oil introduced after an acute myocardial infraction on serum triglycerides and HDL cholesterol. Am J Clin Nutr 2001; 57: 193200.

[45] Obarzanek E, Sacks FM, Vollmer WM, et al. Effects on blood lipids of a blood pressure-lowering diet: the Dietary Approaches to Stop Hypertension (DASH) Trial. Am J Clin Nutr 2001: 74: 80-9.

[46] Singh RB, Dubnov G, Niaz MA, et al. Effect of an IndoMediterranean diet on progression of coronary disease in high risk patients: a randomized single blind trial. Lancet 2002; 360: 145561.

[47] Singh RB, DeMeester F, Mechirova V, Pella D, Otsuka K. Fatty acids in the causation and therapy of metabolic syndrome. Wild type foods in health promotion and disease prevention, In: DeMesster F, Watson, RR, Eds. Humana Press, NJ 2008: pp. 26384 .

[48] Singh RB, Sharma VK, Gupta RK. Nutritional modulators of lipoprotein metabolism in patients with risk factors for coronary heart disease. J Am Coll Nutr 1992; 11: 391-8.

[49] Sampath H, Ntambi JM. Polyunsaturated fatty acid regulation of gene expression. Nutr Rev 2004; 62: 333-9.

[50] Kim HJ, Takahashi M, Ezaki O. Fish oil feeding decreases mature sterol regulatory element-binding protein 1 [SREBP-1] by dowregulation of SREBP-1c mRNA in mouse liver. A possible mechanism for down - regulation of lipogenic enzyme mRNAs. J Biol Chem 1999; 274: 25892-8.

[51] Leaf A, Kang JX, Xiao YF, Billman GE. Clinical prevention of sudden cardiac death by $n-3$ polyunsaturated fatty acid mechanism of prevention arrhythmias by n-3 fish oils. Circulation 2003; 107: 2646-52.

[52] De Caterina R, Madonna R, Zucchi R, La Rovere MT. Antiarrhythmic effects of omega-3 fatty acids: from epidemiology to bedside. Am Heart J 2003; 146: 420-30.

[53] Connor WE, De Franchesco CA, Connor SL. N-3 fatty acids from fish oil: effects on plasma lipoproteins and hypertriglyceridemic patients. Ann N Y Acad Sci 1993; 683: 16-34.

[54] Zampelas A, Peel AS, Gould BJ, Wright J, Williams CM. Polyunsaturated fatty acids of the n-6 and n-3 series: effects on postprandial lipid and apolipoprotein levels in healthy men. Eur J Clin Nutr 1994; 48: 842-8.

[55] Abeywardena MY, Head RJ. Long chain n-3 polyunsaturated fatty acids and blood vessel function. Cardiovasc Res 2001; 52: 361-71.

[56] Hooper L, Thompson RL, Harrison RA, et al. Risks and benefits of omega 3 fats for mortality, cardiovascular disease, and cancer: Systematic review. BMJ 2006; 332: 752-5.

[57] Thirunavukkarasu M, Penumathsa SV, Juhasz B, et al. Niacinbound chromium enhances myocardial protection from ischemiareperfusion injury. Am J Physiol Heart Circ Physiol 2006; 291(2): H820-6.

[58] Roche HM, Gibney MJ. Effect of long-chain n-3 polyunsaturated fatty acids on fasting and postprandial triacylglycerol metabolism. Am J Clin Nutr 2000; 71(1): 232S-7S.

[59] Matsui H, Shimosawa T, Uetake Y, et al. Protective effect of potassium against the hypertensive cardiac dysfunction: association with reactive oxygen species reduction. Hypertension 2006; 48(2): 225-31.

[60] Dallner G, Brismar K, Chojnacki T, Swiezewska E. Regulation of coenzyme Q biosynthesis and breakdown. Biofactors 2003; 18(14): $11-22$.

[61] Calder PC. n-3 Fatty acids and cardiovascular disease: evidence explained and mechanisms explored. Clin Sci (Lond) 2004; 107(1): $1-11$

[62] Harris A, Devaraj S, Jialal I. Oxidative stress, alpha-tocopherol therapy, and atherosclerosis. Curr Atheroscler Rep 2002; 4(5): 373 80 . 
[63] Basu A, Lucas EA. Mechanisms and effects of green tea on cardiovascular health. Nutr Rev 2007; 65(8): 361-75.

[64] Gurley BJ, Swain A, Hubbard MA, et al. Clinical assessment of CYP2D6-mediated herb-drug interactions in humans: effects of milk thistle, black cohosh, goldenseal, kava kava, St. John's wort, and Echinacea. Mol Nutr Food Res 2008; 52(7): 755-63.

[65] Slavin JL. Position of the American Dietetic Association: health implications of dietary fiber. J Am Diet Assoc 2008; 108(10): 1716-31.

[66] Chagan L, Bernstein D, Cheng JW, et al. Use of biological based therapy in patients with cardiovascular diseases in a universityhospital in New York City. BMC Complement Altern Med 2005; 5: 4.

[67] Okuyama H, Ichikawa Y, Sun Y, Hamazaki T, Lands WE. The cholesterol hypothesis - its basis and its faults. World Rev Nutr Diet 2007; 96: 1-17.

[68] Mozaffarian D, Psaty BM, Rimm EB, et al. Fish intake and risk of incident of atrial fibrillation. Circulation 2004; 110: 368-73.

[69] Lane JS, Magno CP, Lane KT, Chan T, Hoyt DB, Greenfield S. Nutrition impacts the prevalence of peripheral arterial disease in the United States. J Vasc Surg 2008; 48(4): 897-904.

[70] Singh RB, Rastogi SS, Ghosh S, Singh R, Niaz MA. Effects of guava intake on serum total and high density lipoprotein cholesterol levels and on systemic blood pressure. Am J Cardiol 1992; 70: 1287-91.

[71] MRC/BHF Heart Protection Study of cholesterol-lowering therapy and of antioxidant vitamin supplementation in a wide range of patients at increased risk of coronary heart disease death: early safety and efficacy experience. Eur Heart J 1999; 20(10): 72541.

[72] NIH State-of-the-Science Conference Statement: Multivitamin/Mineral Supplements and Chronic Disease Prevention, Available from: http://consensus.nih.gov/2006/2006Multivitamin MineralSOS028Statementhtml.htm [Accessed on 15-17 May, 2006].

[73] Heinrich M, Leonti M, Nebel S, Peschel W. Local Food Nutraceuticals: an example of a multidisciplinary research project on local knowledge. J Physiol Pharmacol 2005; 56(S1): 5-22.

[74] Chagan L, Ioselovich A, Asherova L, Cheng JW. Use of alternative pharmacotherapy in management of cardiovascular diseases. Am J Manag Care 2002; 8(3): 270-85.

[75] Wildman REC. Classifying nutraceuticals. In: Wildman REC, Ed. handbook of nutraceuticals and functional foods. CRC series in modern nutrition 2001; pp. 13-30.

[76] McBride BF, Karapanos AK, Krudysz A, Kluger J, Coleman CI, White CM. Electrocardiographic and hemodynamic effects of a multicomponent dietary supplement containing ephedra and caffeine: a randomized controlled trial. JAMA 2004; 291(2): 21621.

[77] Pham DQ, Plakogiannis R. Vitamin E supplementation in cardiovascular disease and cancer prevention: Part 1. Ann Pharmacother 2005; 39(11): 1870-8.

[78] Tran TL. Antioxidant supplements to prevent heart disease. Real hope or empty hype? Postgrad Med 2001; 109(1): 109-14.
[79] Maxwell SR. Coronary artery disease--free radical damage, antioxidant protection and the role of homocysteine. Basic Res Cardiol 2000; 95(1): I65-71.

[80] Borochov-Neori H, Judeinstein S, Greenberg A, et al. Phenolic antioxidants and antiatherogenic effects of Marula (Sclerocarrya birrea Subsp. caffra) fruit juice in healthy humans. J Agric Food Chem 2008; 56(21): 9884-91.

[81] Eastwood MA. Interaction of dietary antioxidants in vivo: how fruit and vegetables prevent disease? QJM 1999; 92(9): 527-30.

[82] Simopoulos AP. Importance of the ratio of omega-6/omega-3 essential fatty acids: evolutionary aspects. World Rev Nutr Diet 2003; 92: 1-22.

[83] Carlsson CM. Homocysteine lowering with folic acid and vitamin B supplements: effects on cardiovascular disease in older adults. Drugs Aging 2006; 23(6): 491-502.

[84] Marchioli R, Barzi F, Bomba E, et al. Early protection against sudden death by $\mathrm{n}-3$ polyunsaturated fatty acids after myocardial infarction: time-course analysis of the results of the Gruppo Italiano per lo Studio della Sopravvivenza nell'Infarto Miocardico (GISSI)-Prevenzione. Circulation 2002; 105(16): 1897-903.

[85] Erdmann K, Cheung BW, Schröder H. The possible roles of foodderived bioactive peptides in reducing the risk of cardiovascular disease. J Nutr Biochem 2008; 19(10): 643-54.

[86] McCarty MF. A taurine-supplemented vegan diet may blunt the contribution of neutrophil activation to acute coronary events. Med Hypotheses 2004; 63(3): 419-25.

[87] Okuyama H, Ichikawa Y, Sun Y, Hamazaki T, Lands WE. New directions of lipid nutrition for the primary and secondary prevention of coronary heart disease and other late-onset diseases. World Rev Nutr Diet 2007; 96: 151-8.

[88] Okuyama H, Ichikawa Y, Sun Y, Hamazaki T, Lands WE. Mechanisms by which dietary fats affect coronary heart diesease mortality. World Rev Nutr Diet 2007; 96: 119-41.

[89] Okuyama H, Ichikawa Y, Sun Y, Hamazaki T, Lands WE. Omega3 fatty acids effectively prevent coronary heart disease and other lateonset diseases - the excessive linoleic acid syndrome. World Rev Nutr Diet 2007; 96: 83-103.

[90] Malinowski JM, Metka K. Elevation of low-density lipoprotein cholesterol concentration with over-the-counter fish oil supplementation. Ann Pharmacother 2007; 41(7): 1296-300.

[91] Alibin CP, Kopilas MA, Anderson HD. Suppression of cardiac myocyte hypertrophy by conjugated linoleic acid: role of peroxisome proliferator-activated receptors alpha and gamma. J Biol Chem 2008; 283(16): 10707-15.

[92] Baker WL, Gutierrez-Williams G, White CM, Kluger J, Coleman CI. Effect of cinnamon on glucose control and lipid parameters. Diabetes Care 2008; 31(1): 41-3.

[93] Szapary PO, Wolfe ML, Bloedon LT, et al. Guggulipid for the treatment of hypercholesterolemia: a randomized controlled trial. J Am Med Assoc 2003; 290(6): 765-72. Available at: http:// www.ayurvediccure.com/guggul.htm

[94] Nohr LA, Rasmussen LB, Straand J. Resin from the mukul myrrh tree, guggul, can it be used for treating hypercholesterolemia? A randomized, controlled study. Complement Ther Med 2009; 1(1): 16-22. 